\title{
Impact of surgical and non-surgical interventions on post-operative recurrence and malignancy transformation rate of Oral Leukoplakia
}

\section{Dominic Beith}

\section{INTRODUCTION}

Oral Leukoplakia (OL) is a common pre-malignant lesion with a global point prevalence of $2.60 \% .{ }^{1,2}$ Defined as a "predominantly white lesion of the oral mucosa that cannot be characterised as any other definable lesion". ${ }^{2-9}$ The lesion is found worldwide with a statistically significant gender prevalence ratio of 3.22.1,10 36\% of dysplastic OL lesions will transform to oral squamous cell carcinoma (OSCC), and those without may still transform $(15 \%) .{ }^{8}$ Because of this markedly high transformation rate, it is imperative that we are able to diagnose this lesion effectively.

Given that leukoplakia is at an increased risk of transformation to OSCC, the associated risk factors for $\mathrm{OL}$ are therefore not too dissimilar to that of OSCC. ${ }^{11,12}$ $\mathrm{OL}$ is significantly more prevalent among those who smoke, including areca nut; a 6-fold increase reported over non-smokers. ${ }^{7}, 11,13,14$

Alcohol-related habits are known as a risk factor for OL and when combined with tobacco, it works synergistically in its development. ${ }^{11}$ Alcohol causes the accumulation of carcinogens ( $N$-nitrosamines) and increases epithelial permeability (15). An in-vitro model of porcine oral mucosa showed a significant increase in permeability to $N$-nitrosonornicotine (tobacco-specific $N$-nitrosamine) at ethanol concentrations $\geq 25 \% .{ }^{16}$

Another cause of OL is from constant irritation producing a mimicking lesion classified as "frictional keratosis". As frictional keratosis is reversible, unlike OL, it will disappear $<4$ weeks from resolution. ${ }^{9}$ Human papilloma virus (HPV) is reported to be a risk factor for cancerous oral lesions however there is limited literature surrounding HPV and OL. 2, 10, 13, 17, 18

\section{CLINICAL MANIFESTATION}

$\mathrm{OL}$ is categorised as homogeneous, often flat and thin, or non-homogeneous, which has three different sub-types:

1. Speckled - the lesion has both a white and red appearance (erythroleukoplakia)

2. Nodular - the lesion has red or white polypoidal outgrowths

3. Verrucous - the lesion has rough surface appearance Proliferative verrucous leukoplakia (PVL) is a form of verrucous leukoplakia which initiates as hyperkeratosis and presents as multifocal exophytic regions. It is untreatable has both high recurrence and malignant transformation rates, transforming into verrucous carcinoma or OSCC over a $10-15$ year period. ${ }^{10,13,19}$

Pindborg et al describes a pre-malignant lesion as a "morphologically altered tissue", whose malignant transformation rate is higher compared to normal mucosa. ${ }^{3}$ The annual malignant transformation rate of $\mathrm{OL}$ to OSCC is $1 \%$, with this rate being higher in nonhomogenous lesions over homogenous. ${ }^{13}$

\begin{tabular}{|l|}
\hline $\begin{array}{l}\text { Risk factors for malignant transformation of } \\
\text { leukoplakia }\end{array}$ \\
\hline Female \\
\hline Long duration of leukoplakia \\
\hline Leukoplakia in non-smokers (idiopathic leukoplakia) \\
\hline Located on tongue and/or floor of the mouth \\
\hline Size $>200 \mathrm{~mm}^{2}$ \\
\hline Non-homogenous variant \\
\hline Presence of $C$. albican \\
\hline Presence of oral epithelial dysplasia (OED) \\
\hline
\end{tabular}

Table 1: Risk factors for the malignant transformation of leukoplakia to oral squamous cell carcinoma or verrucous carcinoma (PVL only). Data reproduced from Table 6 in van der Waal $(2009)^{13}$

The presence of oral epithelial dysplasia (OED), frequently found in erythroleukoplastic lesions, and the extent of dysplasia is the current best marker of a pre-cancerous lesion (Table 1); not all dysplastic lesions progress and some may reverse. ${ }^{7}$

The aim of the structured review is to appraise current and future diagnostic methods. Most importantly, the intention is to determine if recurrence and malignancy transformation rates differ between the interventions available.

\section{DIAGNOSIS}

\section{Histological Typing}

Histological typing is performed from an incisional biopsy of the lesion and then examined under light-microscopy for evidence of dysplasia. ${ }^{8}$ Dysplasia is scored based on the characteristics of the lesion and the level infiltration as mild, moderate or severe., ${ }^{3,9}$ Assuming that more dysplasia increases the likelihood of malignancy, a relationship between OED and malignant transformation rate is difficult to show due to subjectivity between lesions. ${ }^{8}$

Upon examination, homogenous leukoplakias' are hyperkeratotic lesions, no evidence of dysplasia but may exhibit some inflammation of the lamina propria. In contrast, non-homogenous lesions are dysplastic. ${ }^{3}$

\section{lodine-Staining Method}

The iodine-staining method (IOM) can detect OED over white lesions. Iodine is applied and normal mucosa should turn a light brown colour (Table 2). Visualisation of OED is due to the formation of an iodine-glycogen complex. The Warburg effect, states that a malignant tissue will 
have depleted glucose levels due to the increased rate of glycolysis. ${ }^{20}$ Therefore in the presence of OED, there would be reduced glycogen concentrations in the mucosa thus explaining why it remains unstained; highlykeratinised tissues (gingivae) are also unstained. ${ }^{21}$

\section{Auto-Fluorescence Visualisation Method}

Yamamoto et al describes a new method of recognising dysplastic lesions known as auto-fluorescence visualisation method (AVM) that takes advantage of fluorophores contained within the mucosa such as flavin adenine dinucleotide (FAD) and collagen. Blue light is directed onto the area, and through their auto-fluorescent properties emit a green light (Table 2)., 21, 22

Farah et al conducted a study using the commercially available AVM machine, Visually Enhanced Lesion Scope (VELscope). VELscope is able to achieve similar results without irritating the oral mucosa seen in IOM. ${ }^{21,22}$ It produces a blue wavelength of 400-460 $\mathrm{nm}$ and detects green light at $515 \mathrm{~nm}$. OED causes degradation of collagen and a fluorophores, leading to an absence of a detectable emitted frequency (FVL(-) in Figure 1). The use of VELscope and other AVM alike serve as a noninvasive judgement of a lesion's margin. ${ }^{22}$

This field has been previously researched by detecting increases in red light emitted in areas of dysplasia. ${ }^{23} \mathrm{Van}$ Staveren et al reported the use of AVM with artificial neural networks (automated computer algorithm) to group OL based on its sub-type and OED and found 100\% accuracy and $86 \%$ sensitivity towards the lesion. ${ }^{6}$

\section{INTERVENTIONS}

Management of OL can be split into conservative, medical and surgical intervention. Conservative management involves the cessation of tobacco and alcohol habits. Medical management involves the use of retinoids, which are vitamin A derivatives and lead to the down-regulation

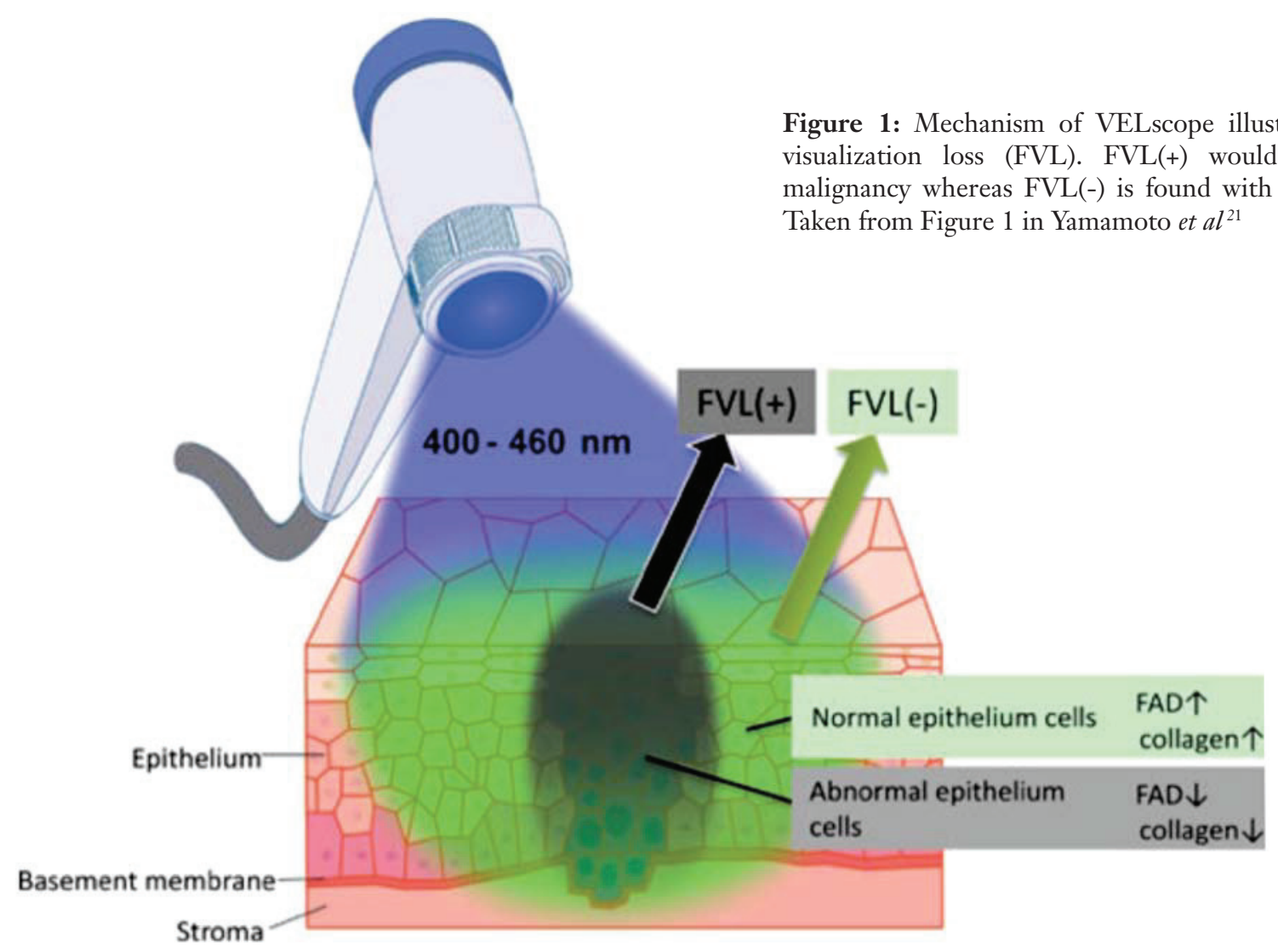

\begin{tabular}{|l|l|l|l|}
\hline Technique & Mechanism & Positive & Negative \\
\hline Histological Typing & Biopsy taken for examination & Dysplasia/OSCC in situ & No evidence of dysplasia \\
\hline $\begin{array}{l}\text { Iodine-Staining } \\
\text { Method }\end{array}$ & $\begin{array}{l}\text { Formation of Iodine- } \\
\text { Glycogen complex }\end{array}$ & $\begin{array}{l}\text { Tissue stained yellow- } \\
\text { brown thus normal } \\
\text { epithelium }\end{array}$ & $\begin{array}{l}\text { Unstained tissue may indicate } \\
\text { presence of malignancy or a highly } \\
\text { keratinised tissue }\end{array}$ \\
\hline $\begin{array}{l}\text { Auto-Fluorescence } \\
\begin{array}{l}\text { Visualisation } \\
\text { Method }\end{array}\end{array}$ & $\begin{array}{l}\text { Fluorophores are auto- } \\
\text { fluorescent when excited by } \\
\text { blue photons at 400-460 nm }\end{array}$ & $\begin{array}{l}\text { Green light emitted at } \\
515 \mathrm{~nm} \text { therefore normal } \\
\text { epithelium }\end{array}$ & $\begin{array}{l}\text { No light emitted due to } \\
\text { breakdown of fluorophores, } \\
\text { suggestive of malignancy }\end{array}$ \\
\hline
\end{tabular}

Table 2: Summary of diagnostic techniques for Oral Leukoplakia. Data taken from ${ }^{3,8,21,22}$ 
of proto-oncogenes and cellular differentiation; the current retinoid for treatment is 13 -cis Retinoic Acid (13cRA). ${ }^{24,25}$

Current best practice for the treatment of OL is surgical resection. Other modalities used include $\mathrm{CO}_{2}$ laser excision, neodymium-doped yttrium aluminum garnet (Nd:YAG) laser evaporation and cryosurgery.

\section{RESULTS}

\begin{tabular}{|c|c|c|c|c|c|}
\hline Reference & Intervention & $\begin{array}{l}\text { Number } \\
\text { of patients }\end{array}$ & $\begin{array}{l}\text { Number } \\
\text { of lesions }\end{array}$ & $\begin{array}{l}\text { Recurrence } \\
\text { rate }(\%)\end{array}$ & $\begin{array}{l}\text { Malignancy } \\
\text { transformation rate (\%) }\end{array}$ \\
\hline Holmstrup et al 25 & Surgical excision & 89 & 94 & $\begin{array}{l}13.48 \\
\text { (12 patients) }\end{array}$ & 12.77 (11 lesions) \\
\hline Kuribayashi et $a l^{26}$ & Surgical excision & 52 & 53 & $\begin{array}{l}15.09 \\
\text { (8 lesions) }\end{array}$ & 1.89 (1 lesion) \\
\hline Van der Hem et al ${ }^{27}$ & $\begin{array}{l}\mathrm{CO}_{2} \text { laser } \\
\text { excision }\end{array}$ & 200 & 282 & $\begin{array}{l}9.93 \\
(28 \text { lesion })\end{array}$ & 1.06 (3 lesions) \\
\hline \multirow[t]{2}{*}{ Del Corso et al ${ }^{28}$} & $\begin{array}{l}\mathrm{CO}_{2} \text { laser } \\
\text { excision }\end{array}$ & 30 & 30 & $\begin{array}{l}13.33 \\
\text { (4 lesions) }\end{array}$ & 0 \\
\hline & $\begin{array}{l}\text { Nd:YAG laser } \\
\text { evaporation }\end{array}$ & 47 & 47 & $\begin{array}{l}38.30 \\
(18 \text { lesions })\end{array}$ & 6.38 (3 lesions) \\
\hline Kawczyk-Krupa et al 29 & Cryotherapy & 37 & 72 & $\begin{array}{l}24.32 \\
\text { (9 patients) }\end{array}$ & 5.41 (2 patients) \\
\hline \multirow[t]{2}{*}{ Hong et al ${ }^{30}$} & $\begin{array}{l}13 \text {-cis retinoic } \\
\text { acid }\end{array}$ & 24 & 24 & N/A & $4.17 \%$ (1 patient) \\
\hline & Placebo & 20 & 20 & N/A & $10 \%$ (2 patients) \\
\hline
\end{tabular}

Table 3: Comparison of included studies illustrating number of patients, number of lesions, recurrence rate and malignancy transformation rate. Adapted from Table 5 in van der Hem et al. ${ }^{27}$ Data taken from ${ }^{25-30}$

\begin{tabular}{|c|c|}
\hline Reference & $\begin{array}{l}\text { Median follow-up } \\
\text { period (months) }\end{array}$ \\
\hline Holmstrup et al 25 & 90 \\
\hline Kuribayashi et $a l^{26}$ & 31 \\
\hline Van der Hem et al ${ }^{27}$ & 52 \\
\hline Del Corso et al ${ }^{28}$ & 60 \\
\hline Kawczyk-Krupa et al ${ }^{29}$ & 52.81 \\
\hline Hong et $a l^{30}$ & 9 \\
\hline
\end{tabular}

Table 4: A comparison of follow-up periods in the compared studies. Data taken from ${ }^{25-30}$

\section{SURGICAL INTERVENTION}

All patients were given either local or general anaesthetic dependent on the lesion's size..$^{25-29}$

Holmstrup et al conducted a retrospective study of 84 patients with 94 oral lesions. Lesions were divided based on classification (Table 5) and on location, with most occupying the base of mouth and buccal surface. Mean lesions size was $486 \mathrm{~mm}^{2}$ and were surgically excised with a margin of 3-5 $\mathrm{mm}$ and depth of 4-5 $\mathrm{mm}$. Lesions were then either closed with sutures or using a local mucosal flap if primary closure was not achievable. ${ }^{25}$

$70 \%$ of non-homogenous leukoplakia, 64\% of homogenous leukoplakia and $56 \%$ of erythroplakias resolved with no recurrence. A recurrence rate of $13.48 \%$ was found from 12 lesions: 8 of which were nonhomogenous, 2 homogenous and 2 erythroplakias. Over 2.7-15.1 years (Table 4), 11 transformed into carcinoma, of which 4 were from the recurrent lesions; $37.5 \%$ (3 out of 8 ) non homogenous and $50 \%$ of the erythroplakias (1 out of 2). ${ }^{25}$

Kuribayashi et al investigated recurrence of $\mathrm{OL}$ after surgical excision through a retrospective study of 52 patients. Participants had an average age of 58.3 


\begin{tabular}{|l|c|c|c|}
\hline Reference & $\begin{array}{l}\text { Homogenous } \\
\text { lesions }\end{array}$ & $\begin{array}{l}\text { Non- } \\
\text { Homogenous }\end{array}$ & Erythroplakia \\
\hline $\begin{array}{l}\text { Holmstrup et al } \\
(2006)^{25}\end{array}$ & 39 & 46 & 9 \\
\hline $\begin{array}{l}\text { Kuribayashi } \text { et } \\
\text { al (2012) }\end{array}$ & 21 & 23 & 0 \\
\hline $\begin{array}{l}\text { van der Hem } \text { et } \\
\text { al (2005) }\end{array}$ & 136 & 61 & 0 \\
\hline $\begin{array}{l}\text { Del Corso et al } \\
(2015)^{28}\end{array}$ & 33 (Group 1) & 14 (Group 1) & 0 \\
\cline { 2 - 4 } & 12 (Group 2) & 9 (Group 2) & 0 \\
\hline
\end{tabular}

contained 18 leukoplakias with no dysplasia, 5 with mild, and 7 with moderate dysplasia. Those treated with Nd:YAG laser evaporation had a greater recurrence rate of $38.30 \%$ compared to $13.30 \%$ with $\mathrm{CO}_{2}$ laser excision. All 3 of the transformed lesions were treated with Nd:YAG laser evaporation. ${ }^{28}$

Kawczyk-Krupa et al studied the outcomes of cryotherapy on 72 white lesions occupying the buccal, gingival and labial mucosas. Lesions were identified either as homogenous and non-homogenous leukoplakia (Table 5). Using a scapular probe and $\mathrm{N}_{2} \mathrm{O}$ : lesions $\leq 4 \mathrm{~cm}$ underwent a single session of 2-4, 40-second applications, larger

Table 5: Comparison of the sub-types of oral leukoplakia in the compared studies. Data taken from ${ }^{25-28}$

years with a mean lesion size of $334 \mathrm{~mm}^{2}$. Lesions were grouped as non-homogenous or homogenous (Table 5). Before surgery, suitable resection margins free of OED were achieved using of Lugol's iodine. A positive result from Lugol's iodine was also noted for comparison in the follow-up. Closure was achieved through a split-skin graft or sutures where feasible.

Patients had a post-operative follow-up length between 6 and 89 months (Table 4). Out of the 53 lesions there were 9 reported recurrences. One transformed to OSCC, thus a malignancy transformation rate of $1.89 \%$. Five out of the 9 lesions were female and 2/3rd of the lesions were homogenous. Lesions with a positive staining margin i.e. presence of OED were found to have a higher recurrence rate compared to a negative margin. ${ }^{26}$

Van de Hem et al reviewed the malignancy transformation rate of 200 patients between 1976 and 2001 who had undergone $\mathrm{CO}_{2}$ laser excision. All 282 lesions were predominantly found at the buccal mucosa or the floor of mouth and were grouped into its sub-types (Table 5). The apparatus was moved so that a defocused laser spot of $1 \mathrm{~mm}$ was produced, with beam strengths of $15-20 \mathrm{~W}^{27}$

Over a mean follow-up period of 52 months (Table 4), $89 \%$ of lesions did not recur. Out of the 282 lesions, 28 recurrences were noted $(9.93 \%)$. In 4 of these lesions they showed an increase in OED compared to their original respective lesions. Recurrences were also found to be 1.8 times more likely in males (18:10). Only 3 cases of OSCC were found presenting between months 7-19 of the followup duration. ${ }^{27}$

Del Corso et al evaluated the outcomes of patients who had undergone Nd:YAG laser evaporation or $\mathrm{CO}_{2}$ laser excision between 2004-13. Two groups were established (Table 5): group 1 consisting of 47 lesions for treatment with $\mathrm{Nd}: \mathrm{YAG}$ laser evaporation and group 2 with 30 lesions for $\mathrm{CO}_{2}$ laser excision. Treatment with $\mathrm{Nd}$ :YAG used a laser of $1064 \mathrm{~nm}$ with a spot of $600 \mu \mathrm{m}$. A beam strength of $9 \mathrm{~W}$ is used on the labia, tongue, and gingival margin and $12 \mathrm{~W}$ elsewhere. Contrasting with Van der Hem et al a different $\mathrm{CO}_{2}$ laser was used for group 2 with a spot of $200 \mu \mathrm{m}$ set to pulse for 0.5 seconds with a rest of 0.1 seconds at $8-15 W^{28}$

Group 1 consisted of 35 lesions with no dysplasia, 11 with mild, and 1 with moderate dysplasia. Group 2 lesions had multiple sessions with a 3 -week rest period. They were followed up twice monthly until no recurrence. A recurrence rate of $24.32 \%$ was reported from 9 lesions, and 2 patients developed OSCC both in different locations to their original lesions. ${ }^{29}$

\section{MEDICAL INTERVENTION}

Hong et al carried out a double-blinded randomised control trial comparing 13-cRA against a placebo. Patients were randomly assigned either 13-cRA or a placebo. Those given 13-cRA took $1-2 \mathrm{mg}$ per $\mathrm{kg}$ of body weight per day for 3 months and then reviewed 3 months later.

As measure of the effectiveness of 13-cRA, the degree of dysplasia present in the epithelium was used for comparison. In 13 out of 24 of patients assigned 13-cRA, a significant reduction in $\mathrm{OED}(\mathrm{P}=0.01)$ was shown compared to only 2 out of the 20 lesions following the placebo. Clinical improvement was also used as a subjective measure of effectiveness. In those treated with 13-cRA, 16 cases showed clinical improvement, and in 8 cases no clinical improvement. Histopathological findings report a positive result in 9 and 4 cases respectively. Most astonishingly, the 3 lesions that entered the trial with severe dysplasia or OSCC had reduced moderate, mild and normal epithelium. Transformation to OSCC occurred in 1 patient with $13-\mathrm{cRA}$ and 2 with placebo. ${ }^{30}$

\section{DISCUSSION}

Unfortunately, there was not consistent distinction of whether OSCC was from recurred lesions or from new lesion. If the recurrent lesion was at or adjacent to the site of treatment, it would be a better measure of how that particular modality was affecting the recurrence and malignancy transformation rates.

Van der Waal states that OL has an annual transformation rate estimated at $1 \%$, worryingly, only $\mathrm{CO}_{2}$ laser excision complies with this figure with malignancy transformation rates of $1.06 \%$ and $0 \%$ for van der Hem et al and Del Corso et al respectively. ${ }^{13,27,28}$

Interestingly, in the study by Holmstrup et al, out of the $36 \%$ of unresolved lesions, $31 \%$ were homogenous leukoplakia compared to $5 \%$ from non-homogenous lesions. They were not able to show that surgical excision deferred malignant transformation, but it did show us that out of the lesions treated, homogenous leukoplakia was less likely to resolve. ${ }^{25}$ 
Lodi and Porter report that the use of $\mathrm{CO}_{2}$ laser excision achieves better aesthetics and functionality of the lesion from a reduction in contractures. ${ }^{31}$ It is reported that the better aesthetic outcomes are linked to an increased chance of spotting OSCC and so an increased chance of resolution of the lesion. However, the aspect of detection is still subjective and may be based on the experience of the clinician. ${ }^{13}$

The use of cryotherapy has a five-fold increase on the malignancy transformation rate $(5.41 \%)$ compared to $\mathrm{CO}_{2}$ laser excision $(1.09 \%) .{ }^{27,} 29$ The high recurrence and malignancy transformation rates may be explained by a study investigating the link between cryotherapy and carcinogenesis in hamster cheek pouches. The results showed an increase in the permeability of carcinogens following cryotherapy and this could be one justification for the high rates. ${ }^{32}$

Kuribayashi et al states that the location of the lesion affects the recurrence rate. The gigival region is thin and highly keratinised hence resection margins of $1.25 \mathrm{~mm}$ can only be achieved; reports suggest at least $3 \mathrm{~mm}$ margin. ${ }^{25-28}$ Lugol's iodine is used not only to identify positive margins but also to identify a safe margin as a positive result indicates presence of OED. ${ }^{26}$ Surgical intervention is only preventative when margins clear of OED are applied. ${ }^{28}$ Lesions that recurred with mainly homogenous fitting with the above evidence that homogenous leukoplakias are more resistant to treatment. ${ }^{27}$

The greatest recurrence rate of $38.30 \%$; was recorded with Nd:YAG laser evaporation; much higher than the other modalities. Given that this is the only paper profiling this treatment, findings may not be representative of others papers. ${ }^{28}$

Hong et al was the only study in this comparison using 13-cRA as treatment; although conducted in 1986, the findings are still relevant. Cheilitis and facial erythema developed in 19 cases and hypertryglycerideaemia in 17. Table 3 illustrates the ability of 13-cRA to regress lesions, which was reported in no other treatment: those with severe dysplasia were able to be reversed to moderate, mild and normal epithelium. With the follow-up time being only 9 months, the long-term effects of 13-cRA have not been well established and so further investigation is needed..$^{30}$

Although all of our studies grouped OL by its subtypes, the number of homogenous lesions to nonhomogenous lesions was not consistent in all studies. Because non-homogenous lesions, in particular PVL, have an increased rate of malignant transformation compared to other lesions, the rates calculated are not truly comparable (Table 5). ${ }^{25}$

Limitations on this comparison (Table 3) are that there are huge discrepancies in median follow-up period (Table 4). Because of this, and the nature of OL transforming into OSCC, it is inevitable that we see differences in the recurrence and malignancy transformation rates treatments. ${ }^{13}$

All of the results compared in Table 3, excluding Hong et al, are gathered from retrospective case report studies. Case report studies compare the effects of treatment, in our case surgical or non-surgical interventions, against a desired outcome. Although they are considered to be at the bottom of the hierarchy of study designs, they are excellent at eliciting the effects of a treatment. For the purpose of this comparison, they are a good way to indicate recurrence and malignancy transformation rate. On the other hand, Hong et al conducted a double-blinded randomised controlled trial; this is considered to be one of the best studies to do in order to eliminate bias from your results. $^{33}$

\section{CONCLUSIONS}

The main premise of this review was to consider the treatment modalities available for OL and come to a conclusion on which offers the lowest recurrence and malignant transformation rates.

It can be seen in Table 3 that the highest malignancy transformation rate $(12.77 \%)$ was achieved using surgical excision and the lowest rate $\left(1.06 \%\right.$ ) seen with $\mathrm{CO}_{2}$ laser excision. ${ }^{25,27}$ From the comparison, the lowest recurrence rate was also found with $\mathrm{CO}_{2}$ laser excision thus illustrating that this is the best treatment for OL. As $\mathrm{CO}_{2}$ laser excision had the largest cohort with 282 lesions, it is arguably the most representative data. ${ }^{27}$

Unfortunately due to the toxicities of 13-cRA as a treatment for OL, it does not have the widespread usage that the surgical interventions do. Given that the paper was published in 1986, newer drugs may provide similar outcomes without the toxicity. It would be interesting to see in the future if a dual-therapy combining both medical (13-cRA) and surgical management for OL changed the recurrence and malignant transformation rate; and to see if it works synergistically with any modality.

My other aim in this study was to consider the current and future diagnostic tools available for OL. One of the major pitfalls of histological typing is the degree of subjectivity between lesions; future methods such as AVM and IOM are also not free from this. The one large difference between current and future methods is that there is now a shift into non-invasive techniques that can be carried out when the patient presents. In my opinion, the future of AVM and in the detection of premalignant lesions such as OL is with artificial intelligence. As mentioned earlier, AVM has already been coupled with an artificial neural network in the detection of OL with $86 \%$ sensitivity and $100 \%$ accuracy. ${ }^{6}$

\section{REFERENCES}

1. Petti S. Pooled estimate of world leukoplakia prevalence: a systematic review. Oral oncology. 2003;39(8):770-80.

2. Parlatescu I, Gheorghe C, Coculescu E, Tovaru S. Oral Leukoplakia - an Update. Mædica. 2014;9(1):8893.

3. Pindborg JJ, Reichart PA, Smith CJ, Van der Waal I. Histological Typing of Cancer and Precancer of the Oral Mucosa. 2 ed: Springer-Verlag Berlin Heidelberg; 1997. p. 21-5.

4. Lopez-Jornet P, Camacho-Alonso F. Comparison of pain and swelling after removal of oral leukoplakia with $\mathrm{CO}(2)$ laser and cold knife: a randomized clinical trial. Medicina oral, patologia oral y cirugia bucal. 2013;18(1):e38-44. 
5. Amagasa T, Yamashiro M, Ishikawa H. Oral Leukoplakia Related to Malignant Transformation. Oral Science International. 2006;3(2):45-55.

6. Van Staveren HJ, Van Veen RLP, Speelman OC, Witjes MJH, Star WM, Roodenburg JLN. Classification of clinical autofluorescence spectra of oral leukoplakia using an artificial neural network: a pilot study. Oral oncology. 2000;36(3):286-93.

7. Warnakulasuriya S, Johnson NW, Van der Waal I. Nomenclature and classification of potentially malignant disorders of the oral mucosa. Journal of Oral Pathology \& Medicine. 2007;36(10):575-80.

8. Martorell-Calatayud A, Botella-Estrada R, BaganSebastian JV, Sanmartin-Jimenez O, Guillen-Barona C. Oral leukoplakia: clinical, histopathologic, and molecular features and therapeutic approach. Actas dermo-sifiliograficas. 2009;100(8):669-84.

9. Brouns ER, Baart JA, Bloemena E, Karagozoglu H, Van der Waal I. The relevance of uniform reporting in oral leukoplakia: definition, certainty factor and staging based on experience with 275 patients. Medicina oral, patologia oral y cirugia bucal. 2013;18(1):e19-26.

10. Van der Waal I. Potentially malignant disorders of the oral and oropharyngeal mucosa; present concepts of management. Oral oncology. 2010;46(6):423-5.

11. Dietrich T, Reichart PA, Scheifele C. Clinical risk factors of oral leukoplakia in a representative sample of the US population. Oral oncology. 2004;40(2):158-63.

12. Lodi G, Sardella A, Bez C, Demarosi F, Carrassi A. Systematic review of randomized trials for the treatment of oral leukoplakia. Journal of dental education. 2002;66(8):896-902.

13. Van der Waal I. Potentially malignant disorders of the oral and oropharyngeal mucosa; terminology, classification and present concepts of management. Oral oncology. 2009;45(4-5):317-23.

14. Baric JM, Alman JE, Feldman RS, Chauncey HH. Influence of cigarette, pipe, and cigar smoking, removable partial dentures, and age on oral leukoplakia. Oral Surgery, Oral Medicine, Oral Pathology. 1982;54(4):424-9.

15. Andre K, Schraub S, Mercier M, Bontemps P. role of alcohol and tobacco in the aetiology of head and neck cancer: A case-control study in the doubs region of France. European Journal of Cancer Part B: Oral Oncology. 1995;31(5):301-9.

16. Du X, Squier CA, Kremer MJ, Wertz PW. Penetration of N-nitrosonornicotine (NNN) across oral mucosa in the presence of ethanol and nicotine. Journal of oral pathology \& medicine : official publication of the International Association of Oral Pathologists and the American Academy of Oral Pathology. 2000;29(2):80-5.

17. Bhargava A, Shakeel M, Srivastava A, Raza T, Rizvi S, Varshney P. Role of human papilloma virus in oral leukoplakia. (Original Article). Indian Journal of Cancer. 2016;53(1):206.

18. Saghravanian N, Ghazvini K, Babakoohi S, Firooz A, Mohtasham N. Low prevalence of high risk genotypes of human papilloma virus in normal oral mucosa, oral leukoplakia and verrucous carcinoma. Acta Odontologica Scandinavica. 2011;69(6):406-9.

19. Bagan J, Scully C, Jimenez Y, Martorell M. Proliferative verrucous leukoplakia: a concise update. Oral diseases. 2010;16(4):328-32.
20. Vander Heiden MG, Cantley LC, Thompson CB. Understanding the Warburg Effect: The Metabolic Requirements of Cell Proliferation. Science (New York, NY). 2009;324(5930):1029-33.

21. Yamamoto N, Kawaguchi K, Fujihara H, Hasebe M, Kishi Y, Yasukawa M, et al. Detection accuracy for epithelial dysplasia using an objective autofluorescence visualization method based on the luminance ratio. International journal of oral science. 2017;9(11):e2.

22. Farah CS, McIntosh L, Georgiou A, McCullough MJ. Efficacy of tissue autofluorescence imaging (VELScope) in the visualization of oral mucosal lesions. Head \& neck. 2012;34(6):856-62.

23. Roblyer D, Kurachi C, Stepanek V, Williams MD, El-Naggar AK, Lee JJ, et al. Objective detection and delineation of oral neoplasia using autofluorescence imaging. Cancer prevention research (Philadelphia, Pa). 2009;2(5):423-31.

24. Ribeiro AS, Salles PR, da Silva TA, Mesquita RA. A Review of the Nonsurgical Treatment of Oral Leukoplakia. International Journal of Dentistry. 2010;2010:10.

25. Holmstrup P, Vedtofte P, Reibel J, Stoltze K. Longterm treatment outcome of oral premalignant lesions. Oral oncology. 2006;42(5):461-74.

26. Kuribayashi Y, Tsushima F, Sato M, Morita K, Omura K. Recurrence patterns of oral leukoplakia after curative surgical resection: important factors that predict the risk of recurrence and malignancy. Journal of oral pathology \& medicine : official publication of the International Association of Oral Pathologists and the American Academy of Oral Pathology. 2012;41(9):682-8.

27. van der Hem PS, Nauta JM, van der Wal JE, Roodenburg JL. The results of CO2 laser surgery in patients with oral leukoplakia: a 25 year follow up. Oral oncology. 2005;41(1):31-7.

28. Del Corso G, Gissi DB, Tarsitano A, Costabile E, Marchetti C, Montebugnoli L, et al. Laser evaporation versus laser excision of oral leukoplakia: A retrospective study with long-term follow-up. Journal of CranioMaxillo-Facial Surgery. 2015;43(6):763-8.

29. Kawczyk-Krupka A, Waśkowska J, RaczkowskaSiostrzonek A, Kościarz-Grzesiok A, Kwiatek S, Straszak D, et al. Comparison of cryotherapy and photodynamic therapy in treatment of oral leukoplakia. Photodiagnosis and Photodynamic Therapy. 2012;9(2):148-55.

30. Hong WK, Endicott J, Itri LM, Doos W, Batsakis JG, Bell R, et al. 13-cis-Retinoic Acid in the Treatment of Oral Leukoplakia. New England Journal of Medicine. 1986;315(24):1501-5.

31. Lodi G, Porter S. Management of potentially malignant disorders: evidence and critique. Journal of oral pathology \& medicine : official publication of the International Association of Oral Pathologists and the American Academy of Oral Pathology. 2008;37(2):63-9.

32. Pospisil OA, MacDonald DG. The tumour potentiating effect of cryosurgery on carcinogen treated hamster cheek pouch. The British journal of oral surgery. 1981;19(2):96-104.

33. Petrisor BA, Bhandari M. The hierarchy of evidence: Levels and grades of recommendation. Indian Journal of Orthopaedics. 2007;41(1):11-5.

Correspondence to: d.beith@lancaster.ac.uk 